\title{
Analysis and Comparison of Urban Air Quality Management in China, Korea and Thailand
}

\author{
Ronghua $\mathrm{Xu}^{1}$, Yanpeng $\mathrm{Cai}^{1,2, *}{\text { Jun } \text { Zheng }^{3} \text { and Hong Wang }}^{4}$ \\ ${ }^{1}$ State Key Laboratory of Water Environment Simulation, School of Environment, Beijing Normal University, Beijing 100875, China \\ ${ }^{2}$ Institute for Energy, Environment and Sustainable Communities, University of Regina, Regina Saskatchewan, Canada \\ ${ }^{3}$ China-ASEAN Environmental Cooperation Centre, Ministry of Environmental Protection, Beijing, China \\ ${ }^{4}$ State Key Laboratory of Earth Surface Processes and Resource Ecology, College of Resources Science and Technology, Beijing \\ Normal University, Beijing, China
}

\begin{abstract}
In the past few years, the problems of urban air pollution became increasingly serious in many countries. In this paper, the comparison and analysis of air quality between developed and developing countries, such as Korea, China, and Thailand, were proposed. In detail, the state of air quality, state of air quality monitoring stations, the standards of air quality, and air quality index classification in the three countries were analyzed. China had 1426 air quality monitoring stations, the most of among the three countries. It was concluded that particle pollution especially $\mathrm{PM}_{2.5}$ and ozone pollution became the main pollution in the three countries. In comparison with the other two countries air quality standard, the first grade of air quality standard in China was the most rigorous. However, the second grade in China was lower than the ones of other two countries. The air quality standards of $\mathrm{PM}_{2.5}$ in Korea and Thailand were merely same. Meanwhile, the standards of ozone and $\mathrm{PM}_{10}$, in Korea were tougher than the ones in Thailand. In terms of air quality index, China had a more delicate air quality index classification than the other two countries.
\end{abstract}

\section{Introduction}

Urban air pollution is a severe problem in the world ${ }^{[1]}$. With the increasing rate of urbanization and industrialization, especially in developing countries, has led to great levels of air pollution ${ }^{[2]}$. Regional air pollution thus raises both governmental and public concerns ${ }^{[3]}$. Air pollutants such as sulfur dioxide $\left(\mathrm{SO}_{2}\right)$, particulate matter $\left(\mathrm{PM}_{10}\right)$ and nitrogen oxides $(\mathrm{NOx})$ are mainly responsible for the air pollution problems ${ }^{[3]}$. The quality of air plays an important role in providing us a good life, and supporting the valuable natural resource and natural environment ${ }^{[4]}$. Air quality improvement is a crucial task, as it affects all aspects of our life ${ }^{[5]}$.As a result, improving air quality becomes an important environmental challenge nowadays ${ }^{[6]}$.

In recent years, air quality management has become a significant issue in public policies all over the world ${ }^{[7]}$. However, air quality policies varied with economic development conditions of countries. Developed countries, such as Korea, introduced rigorous standards to reduce air pollution. Whereas, developing countries such as Thailand and China, which suffered from severe air pollution at present, are trying to build their environmental management systems ${ }^{[8]}$. Because developing countries undergo urbanization, it is significant to carry out air management systems to mitigate air pollution ${ }^{[9]}$.

Meanwhile, to conduct integrated supervision and management of atmospheric pollution, air pollution supervising systems of many cities in the world were founded on agreed standards, air quality index classification and air quality monitoring system ${ }^{[10]}$. Therefore, the aim of this paper is to compare the air quality management of the three countries (i.e., China, Korea and Thailand) in monitoring system, air quality index classification and air quality standards. The response of air quality standard and air quality index classification in the three countries will be also analyzed.

\section{The background of urban air quality in the three countries}

\subsection{China}

In China, with the rapid population growth and economic development in some cities, poor air quality became one of the major environmental concerns affecting the general public such as high particulate matter (PM) concentrations ${ }^{[11]}$. Particularly, in recent years, as to many large-scale emergence of haze-fog weather and $\mathrm{PM}_{2.5}$ becomes one of the vital pollution factors ${ }^{[12]}$. In the last three decades of China, enormous fossil fuel consumption has produced a great deal of volatile organic compounds and nitrogen oxides, thus ozone concentrations have increased drastically ${ }^{[13]}$.

In figure 1 and figure 2 , it can be concluded that except $\mathrm{O}_{3}$, the other five pollutants concentration in 2014 was lower than in 2013. The particular matter $\left(\mathrm{PM}_{10}\right.$ and $\mathrm{PM}_{2.5}$ ) which exceeded standards became the major pollutants in China ${ }^{[14,15]}$.

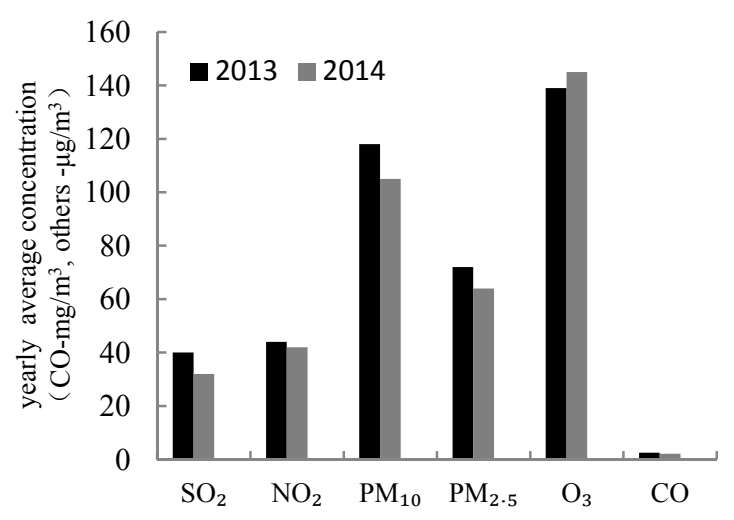

Figure. 1 Comparison of annual average concentration on the first-stage cities of implementing China new standards 


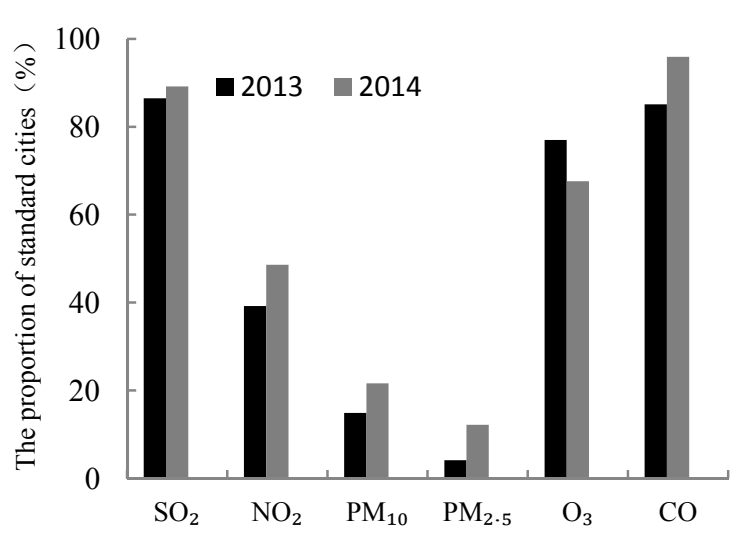

Figure. 2 Comparison of reaching standard proportion on the first-stage cities of implementing China new standards

\subsection{Korea}

Korea appeared the high ozone phenomenon. In addition, the background ozone concentration has increased continuously ${ }^{[16]}$. In Korea, previous studies and government management on particulate matter (PM) tended to focus on $\mathrm{PM}_{10}$ size fraction, although the recent studies have examined both $\mathrm{PM}_{10}$ and $\mathrm{PM}_{2.5}{ }^{[17]}$.

From figure 3 and figure $4, \mathrm{SO}_{2}$ was at below onethird of the air quality standard of $0.02 \mathrm{ppm}$ for over ten years. The $\mathrm{NO}_{2}$ concentration maintained less than the air quality standard of $0.03 \mathrm{ppm}$. The atmospheric lead concentration was $0.0391 \mu \mathrm{g} / \mathrm{m}^{3}$, which was far less than the air quality standard of $0.5 \mu \mathrm{g} / \mathrm{m}^{3}$. However, the $\mathrm{PM}_{10}$ concentration was scarcely lower than the air quality standard of $50 \mu \mathrm{g} / \mathrm{m}^{3}$. The CO concentration was 0.5 ppm, which dropped gradually in the fourteen years. The $\mathrm{O}_{3}$ concentration was $0.026 \mathrm{ppm}$ which went up progressively in the fourteen years ${ }^{[18]}$.

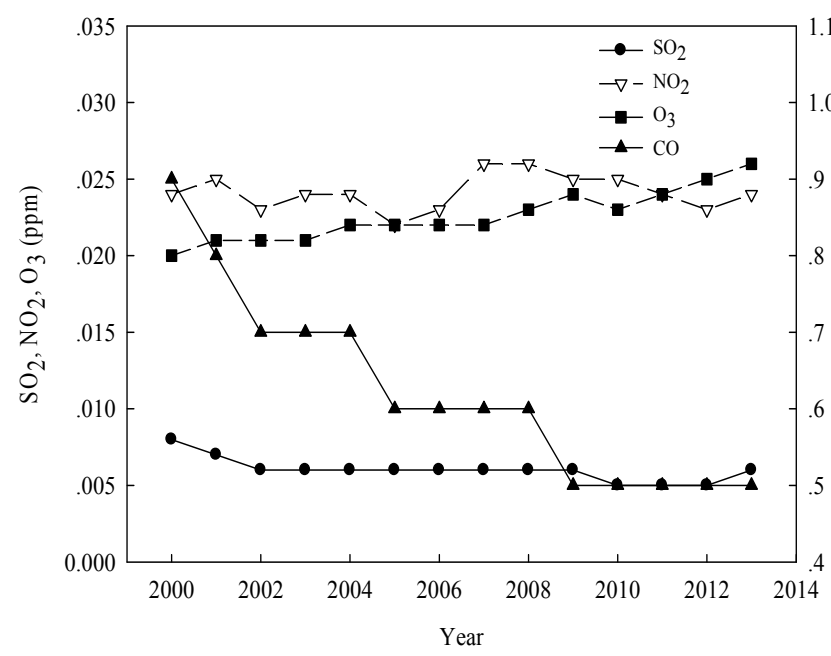

Figure. 3 The annual average concentration of $\mathrm{SO}_{2}, \mathrm{NO}_{2}, \mathrm{O}_{3}$ and $\mathrm{CO}$ in Korea

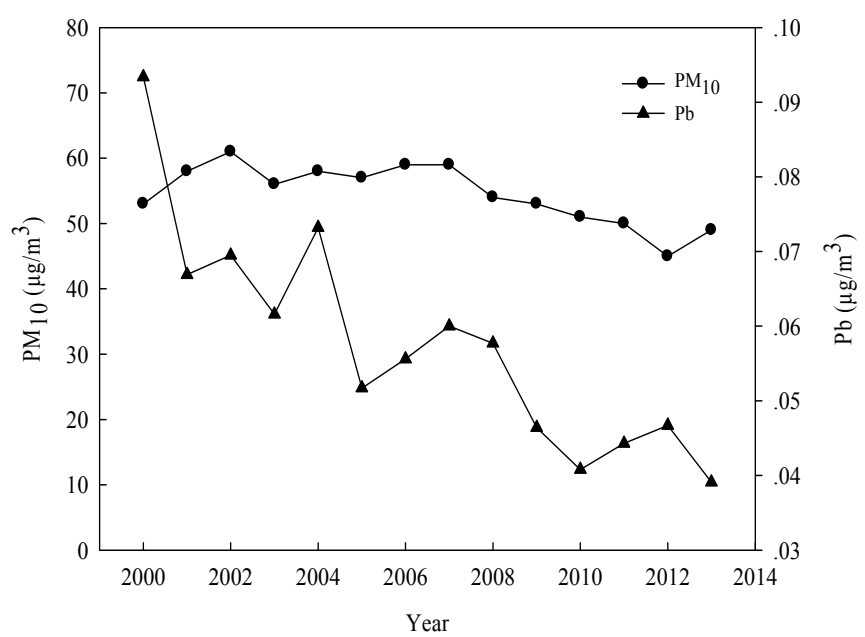

Figure. 4 The annual average concentration of $\mathrm{PM}_{10}$ and $\mathrm{Pb}$ in Korea

\subsection{Thailand}

Located in a tropical region, Thailand is coupled with year-round sunlight. Due to the intense emission of air pollution, the country was subjected to excessive tropospheric $\mathrm{O}_{3}$ production ${ }^{[19]}$. Meanwhile, because of massive biomass burning, the geographical and meteorological conditions give rise to the high levels of particulate matter (PM) in the air of many cities in Thailand ${ }^{[20]}$.

From figure 5, it can be concluded that except $\mathrm{SO}_{2}$, the other five pollutants concentration in 2011 was lower than in 2013 in Thailand. The concentration of ozone $\left(\mathrm{O}_{3}\right)$ and $\mathrm{PM}_{10}$ had exceeded the standards. Thus, ozone $\left(\mathrm{O}_{3}\right)$ and $\mathrm{PM}_{10}$ became major air pollutants in most cities of Thailand. The concentration of other air pollutants (i.e., $\mathrm{SO}_{2}, \mathrm{NO}_{2}$ and $\mathrm{CO}$ ) was lower than the standards in $2013^{[21,22]}$.

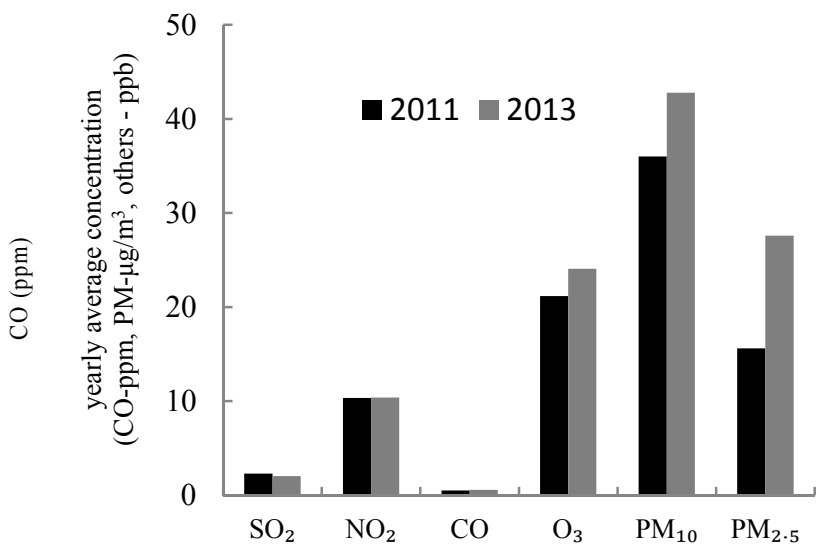

Figure. 5 Comparison of annual average concentration of six main pollutants in Thailand 


\section{Results and discussion}

\subsection{The standard comparison of important pollutants in the three countries}

\subsubsection{Ozone $\left(\mathrm{O}_{3}\right)$}

The air quality standards in Korea and Thailand were much loose than the first grade of China. However, the related standards of Korea and Thailand were tougher than the second grade of air quality standards China (Table 1).

\subsection{2 $P M_{10}$}

Korea and Thailand had a more stringent air quality standard than China's second grade standard. However, first grade standard in China was obviously stricter than the one in other two countries (Table 2).

\subsection{3 $P M_{2.5}$}

Korea and Thailand had a more stringent air quality standard than China's second grade standard. However, first grade standard in China was obviously stricter than the one in the other two countries. The $\mathrm{PM}_{2.5}$ standard of Korea and Thailand were the same (Table 2).

Table 1. Comparison of ozone air quality standards in China, Korea and Thailand (unit: $\mathrm{mg} / \mathrm{m}^{3}$ )

\begin{tabular}{|c|c|c|}
\hline Pollutants & \multicolumn{2}{|c|}{$\mathbf{O}_{3}$} \\
\hline Average time & 8-Hr Average & 1-Hr Average \\
\hline China(I) $*$ & 0.10 & 0.16 \\
\hline China (II) $*$ & 0.16 & 0.20 \\
\hline Korea & 0.12 & 0.20 \\
\hline Thailand & 0.14 & 0.20 \\
\hline
\end{tabular}

*Note: China (I) represents first grade air quality standard of China China (II) represents second grade air quality standard of China

(Source: CNEMC, MOE and PCD)

Table 2. Comparison of particulate matter air quality standards in China, Korea and Thailand (unit: $\mu \mathrm{g} / \mathrm{m}^{3}$ )

\begin{tabular}{|c|c|c|c|c|}
\hline Pollutants & $\mathbf{P M}_{10}$ & $\mathbf{P M}_{2.5}$ & $\mathbf{P M}_{10}$ & $\mathbf{P M}_{2.5}$ \\
\hline Average time & \multicolumn{2}{|c|}{ Yearly Average } & \multicolumn{2}{|c|}{ 24-Hr Average } \\
\hline China $(\mathrm{I}) *$ & 40 & 15 & 50 & 35 \\
\hline China (II) * & 70 & 35 & 150 & 75 \\
\hline Korea & 50 & 25 & 100 & 50 \\
\hline Thailand & 50 & 25 & 120 & 50 \\
\hline
\end{tabular}

(Source: CNEMC, MOE and PCD)

\subsection{Making a comparison on air quality monitoring stations state in the three countries}

China had the largest number of monitoring stations among the three countries; and Korea and Thailand were the next. In Beijing city of China, there were 35 monitoring stations. In the capital of Korea, 45 monitoring stations were installed. In the capital of Thailand, 21 air quality monitoring stations were installed (Table 3).

Table 3. Number of monitoring stations in the three countries and their capital areas

\begin{tabular}{|c|c|c|}
\hline Country & Captital area (stations) & $\begin{array}{c}\text { country } \\
\text { (stations) }\end{array}$ \\
\hline China & Beijing(35) & 1436 \\
\hline Korea & Seoul(45) & 497 \\
\hline Thailand & Bangkok(21) & 66 \\
\hline
\end{tabular}

(Source: CNEMC, MOE and PCD)

\subsection{Comparison of air quality index classification in the three countries}

According to AQI (air quality index) specified by the China National Environmental Monitoring Center (CNEMC), the levels of AQI (in number) was illustrated and divided into 6 classes in China. CAI (comprehensive air-quality index) was broken into 4 classes by ministry of environment (MOE) in Korea, while in Thailand AQI was divided into 5 classes by the pollution control department (PCD). In terms of the first and the second grades, the air quality of all the three countries reached their standard if the AQI or CAI was less than 100. In terms of contamination, China is more delicate than the other two countries. In the three countries, the levels of air quality are described by multiple colours (table 4).

In Korea, calculate the value of the CAI by pollutants. The higher of CAI value, the greater level of air pollution. In the values of the several air pollutants, the highest is the CAI value. Similarly, in China and Thailand, the highest value of several air pollutants is the AQI value.

$$
I_{P}=\frac{I_{H I}-I_{L O}}{B P_{H I}-B P_{L O}} \times\left(C_{P}-B P_{L O}\right)+I_{L O}
$$

Where, $I p=$ the air quality index for each target pollutant $\mathrm{Cp}=$ the rounded concentration of each target pollutant $\mathrm{BP}_{\mathrm{HI}}=$ the breakpoint that is greater than or equal to $\mathrm{Cp}$ $\mathrm{BP}_{\mathrm{LO}}=$ the breakpoint that is less than or equal to $\mathrm{Cp}$ $\mathrm{I}_{\mathrm{HI}}=$ the index value corresponding to $\mathrm{BP}_{\mathrm{HI}}$ $\mathrm{I}_{\mathrm{LO}}=$ the index value corresponding to $\mathrm{BP}_{\mathrm{LO}}$ 
Table 4. Air quality index and relevant information in China, Korea and Thailand

\begin{tabular}{|c|c|c|c|}
\hline Country & AQI/CAI & Description & Colour \\
\hline \multirow{4}{*}{ China } & $0-50$ & excellent & green \\
\cline { 2 - 4 } & $51-100$ & good & yellow \\
\cline { 2 - 4 } & $101-150$ & mild contamination & orange \\
\cline { 2 - 4 } & $151-200$ & $\begin{array}{c}\text { moderate } \\
\text { contamination }\end{array}$ & red \\
\cline { 2 - 4 } & $201-300$ & $\begin{array}{c}\text { heavily } \\
\text { contamination }\end{array}$ & purple \\
\cline { 2 - 4 } & $>300$ & $\begin{array}{c}\text { serious } \\
\text { contamination }\end{array}$ & $\begin{array}{c}\text { brown } \\
\text { red }\end{array}$ \\
\hline \multirow{5}{*}{ Korea } & $0-50$ & good & blue \\
\cline { 2 - 4 } & $51-100$ & moderate & green \\
\cline { 2 - 4 } & $101-250$ & unhealthy & yellow \\
\cline { 2 - 4 } & $251-500$ & very unhealthy & red \\
\hline \multirow{5}{*}{ Thailand } & $0-50$ & good & sky blue \\
\cline { 2 - 4 } & $51-100$ & moderate & green \\
\cline { 2 - 4 } & $101-200$ & unhealthy & yellow \\
\cline { 2 - 4 } & $201-300$ & very unhealthy & orange \\
\cline { 2 - 4 } & $>300$ & hazardous & red \\
\hline
\end{tabular}

(Source: CNEMC, $\mathrm{AK}^{[23]}$ and PCD)

\section{Conclusions}

As urban air pollution raises both public and governmental concerns, improving air quality becomes an important environmental challenge at present. In this paper, air monitoring systems, air quality index classification and air quality standards in China, Korea and Thailand were compared to reflect the characteristics of air pollution management between developing and developed countries. It was concluded that particle pollution especially $\mathrm{PM}_{2.5}$ and ozone pollution became the main pollution in the three countries. In air quality standards, China should continue the first class of air quality standard and continually improve the second class of air quality standard. In terms of air quality index, China had a more delicate air quality index classification than the other two countries. Because air pollution can be transferred to surrounding countries, it is essential to broaden the system boundary of air pollution management. The future study would be furthered in this area.

\section{Acknowledgements}

This work was supported by the National Science \& Technology Pillar Program, China (No. 2012BAC05B02), and National Science Foundation for Innovative Research Group (No. 51121003)

\section{References}

[1] B. Sivertsen, A. Bartonova, Chem. Ind. Chem. Eng. Q. 18, 667 (2012)
[2] M.H. Sowlat, H. Gharibi, M. Yunesian, M.T. Mahmoudi, S. Lotfi, Atmos. Environ. 45, 2050 (2011)

[3] Y. Lv, G.H. Huang, Y.P. Li, Z.F. Yang, W. Sun, J. Environ. Manage. 92, 813 (2011)

[4] M. Everard, B. Pontin, T. Appleby, C. Staddon, E.T. Hayes, J.H. Barnes, J.W.S. Longhurst, Environ. Sci. Policy 33, 355 (2013)

[5] K. Kuklinska, L. Wolska, J. Namiesnik, Atmos. Pollut. Res. 6, 129 (2015)

[6] J.M. Baldasano, M. Goncalves, A. Soret, P. Jimenez-Guerrero, Atmos. Environ. 44, 2997 (2010)

[7] T. Mandal, A.K. Gorai, G. Pathak, Environ. Monit. Assess. 184, 6187 ( 2012)

[8] K. Kuklinska, L. Wolska, J. Namiesnik, Atmos. Pollut. Res. 6, 129 (2015)

[9] B. Xu, S. Zhou, L. Hao, Energ. Policy 83, 109 (2015)

[10]K. Karatzas, N. Moussiopoulos, Environ. Monit. Assess. 65, 451 (2000)

[11]T. Wang, F. Jiang, J. Deng, Y. Shen, Q. Fu, Q. Wang, Y. Fu, J. Xu, D. Zhang, Atmos. Environ. 58, 70 (2012)

[12]L.Li, D.J. Liu, Int. J. Env. Res. Pub. He. 11, 8910 (2014)

[13]X.Yuan, V. Calatayud, L. Jiang, W.J. Manning, F. Hayes, Y. Tian, Z. Feng, Environ. Pollut. 205, 199 (2015)

[14] China National Environmental Monitoring Center (CNEMC): http://www.cnemc.cn/ Report on the State of the Environment in China 2013

[15]China National Environmental Monitoring Center (CNEMC): http://www.cnemc.cn/ Report on the State of the Environment in China 2014

[16]J.B. Lee, J.S. Cha, S.C. Hong, J.Y. Choi, J.S. Myoung, R.J. Park, J.H. Woo, C. Ho, J.S. Han, C.K. Song, Atmos. Environ. 106, 336 (2015)

[17]D.U. Park, K.C. Ha, Environ. Int. 34, 630 (2008)

[18]Ministry of Environment (MOE): http://eng.me.go.kr/eng/web/main.do Environmental Statistics Yearbook 2014

[19]J. Suthawaree, Y. Tajima, A. Khunchornyakong, S. Kato, A. Sharp, Y. Kajii, Atmos. Res. 104, 245 (2012).

[20]T. Chuesaard, T. Chetiyanukornkul, T. Kameda, K. Hayakawa, A. Toriba, Aerosol Air Qual. Res. 14, 1248 (2014)

[21]Ministry of Natural Resources and Environment: Pollution Control Department (PCD): http://www.pcd.go.th/info_serv/en_air.html Thailand state of pollution report $2 \overline{0} 13$

[22] Ministry of Natural Resources and Environment: Pollution Control Department (PCD): http://www.pcd.go.th/info_serv/en_air.html Thailand state of pollution report 2011

[23] Air Korea (AK): http://www.airkorea.or.kr/eng/ 